\title{
CORRECTION
}

\section{Correction to: Cerebral perfusion abnormalities in patients with persistent postural-perceptual dizziness (PPPD): a SPECT study}

\author{
Seunghee $\mathrm{Na}^{1} \cdot$ Jooyeon Jamie $\mathrm{Im}^{2} \cdot$ Hyeonseok Jeong ${ }^{2} \cdot$ Eek-Sung Lee $^{3} \cdot$ Tae-Kyeong Lee $^{3} \cdot$ Yong-An Chung ${ }^{2}$. \\ In-Uk Song ${ }^{1}$
}

Published online: 7 February 2019

๑) Springer-Verlag GmbH Austria, part of Springer Nature 2019

\section{Correction to: Journal of Neural Transmission https://doi.org/10.1007/s00702-018-1948-3}

The authors inadvertently forgot to provide the following funding information in the original publication: This research was supported by the Basic Science Research Program through the National Research Foundation of Korea (NRF), funded by the Ministry of Science and ICT (2018R1A6A3A11041118).

Publisher's Note Springer Nature remains neutral with regard to jurisdictional claims in published maps and institutional affiliations.

The original article can be found online at https://doi.org/10.1007/ s00702-018-1948-3.

Yong-An Chung nm@catholic.ac.kr

$\triangle$ In-Uk Song siuy@catholic.ac.kr

1 Department of Neurology, College of Medicine, The Catholic University of Korea, Seoul, South Korea

2 Department of Radiology, College of Medicine, The Catholic University of Korea, Seoul, South Korea

3 Department of Neurology, Soonchunhyang University College of Medicine, Bucheon, South Korea 